\title{
Configuração espacial em cidades aglomeradas: explorando os efeitos da atratividade do terciário na região da Serra Gaúcha, RS
}

Spatial configuration in urban agglomerations: effects of retailing attractiveness in Serra Gaúcha Region, Brazil

\author{
Ana Lilian Brock de Souza[a] (ㄱ, Clarice Maraschin[a] (1)
}

[a] Universidade Federal do Rio Grande do Sul (UFRGS), Programa de Pós-graduação em Planejamento Urbano e Regional (PROPUR), Porto Alegre, RS, Brasil.

Como citar: Souza, A. L. B., \& Maraschin, C. (2019). Configuração espacial em cidades aglomeradas: explorando os efeitos da atratividade do terciário na região da Serra Gaúcha, RS. urbe. Revista Brasileira de Gestão Urbana, 11, e20180061. https://doi.org/10.1590/2175-3369.011.e20180061

\section{Resumo}

O trabalho aborda as aglomerações urbanas e seus possíveis efeitos na estrutura espacial das cidades que as compõem. Uma aglomeração urbana pressupõe a existência de fortes inter-relações socioespaciais entre cidades próximas e complementaridade entre atividades (habitação, emprego, estudo, serviços, entre outras). 0 objetivo deste trabalho é analisar os prováveis efeitos da atratividade entre cidades aglomeradas, nas escalas intra e interurbana. 0 artigo enfoca especificamente a relação habitação-consumo e toma como estudo empírico três cidades aglomeradas na região da Serra Gaúcha (Bento Gonçalves, Garibaldi e Carlos Barbosa). A metodologia do trabalho é de natureza quantitativa e se fundamenta em modelos configuracionais urbanos. As três cidades são representadas como um sistema espacial possibilitando a análise de dois cenários: as cidades separadas e em conjunto. Aplica-se o Modelo de Polaridade como indicador de atratividade relativa, que permite inferir um determinado tipo de complementaridade entre unidades do espaço urbano. A metodologia permitiu a comparação entre os cenários, fornecendo uma primeira medida da hierarquia espacial gerada na relação de consumo entre as cidades. As conclusões procuram evidenciar as potencialidades e limites da metodologia apresentada.

Palavras-chave: Aglomerações urbanas. Modelos configuracionais. Atividades terciárias. Impactos.

\section{Abstract}

This paper focuses on the urban agglomerations and their effects on the spatial structure of the individual cities. An urban agglomeration implies the existence of strong socio-spatial relationships between nearby cities and complementarity between activities (housing, employment, study, services, among others). The objective of this paper is to present a methodology for the analysis of the probable effects of attractiveness between agglomerated cities, in intra-urban and regional scales. The article specifically focuses on the housing-consumption relationship and takes three agglomerated cities in the region of Serra Gaúcha (Bento Gonçalves, Garibaldi and Carlos Barbosa) as an empirical study. The paper applies a quantitative approach based on urban configurational models. The three cities are represented as a spatial

ALBS é arquiteta e urbanista, mestre em Planejamento Urbano e Regional, e-mail: brock.lilian@gmail.com

CM é doutora em Planejamento Urbano e Regional, professora associada do PROPUR-UFRGS, e-mail: clarice.maraschin@ufrgs.br 
system enabling the analysis of two scenarios: individual cities and the unified system. The Polarity model is used as an indicator of the relative attractiveness, inferring a certain type of complementarity between urban space units. The methodology enabled the comparison between the scenarios, providing a first measure of the spatial hierarchy generated for the consumption among the cities. The conclusions seek to highlight the potentialities and limits of the presented methodology.

Keywords: Urban agglomeration. Configurational models. Retail and services. Impacts.

\section{Introdução}

As cidades contemporâneas vêm apresentando dados expressivos de crescimento populacional e expansão territorial, impulsionados principalmente pelo intenso processo de urbanização ocorrido no século XX. No mesmo período, as articulações socioeconômicas e fluxos entre as cidades se acentuaram, em especial devido aos avanços tecnológicos na área das telecomunicações e dos transportes, gerando uma série de vínculos de interdependência entre elas. Por exemplo, no caso brasileiro, Delgado et al. (2016) verificaram que o número de pessoas que se deslocam para outro município para trabalhar e/ou estudar teve, na última década, um aumento superior a 100\%, envolvendo 15,4 milhões de pessoas.

É nesse cenário que a importância das aglomerações urbanas se evidencia, sobretudo quantitativamente, no território nacional (Motta \& Ajara, 2001). 0 conceito de aglomeração urbana se refere a situações em que localidades independentes, em termos político-administrativos, criam relações de interdependência entre si, implicando no aparecimento de uma nova unidade territorial com características próprias (Villaça, 2001).

Do ponto de vista econômico, as aglomerações são fomentadas pela obtenção de vantagens locacionais provenientes da concentração e proximidade de usos (Richardson, 1973; Anas et al., 1998). Do ponto de vista espacial, a inter-relação entre as atividades cria potenciais de desenvolvimento diferenciado em partes específicas das cidades envolvidas, podendo se refletir em alterações tais como valorização imobiliária, densidades demográficas, verticalização, mudanças nas centralidades, demanda por transporte público, entre outros possíveis efeitos (Villaça, 2001).

A inter-relação sócio-espacial entre cidades próximas envolve a complementaridade entre atividades de moradia, trabalho, estudo, consumo, lazer, entre outras. No Brasil, o IBGE vem pesquisando esse tema desde a década de 1970, contribuindo para caracterizar e classificar as aglomerações urbanas, identificando hierarquias e áreas de influência. No entanto, há dificuldades de compreensão dessa interação complexa e, principalmente, de seus possíveis efeitos na estrutura espacial das cidades aglomeradas, demandando abordagens e metodologias adequadas o tratar desse tema. Tal conhecimento é importante do ponto de vista do planejamento urbano, metropolitano e regional, contribuindo para identificar e encaminhar problemas comuns e também explorar as potencialidades das aglomerações. A homologação, em janeiro de 2015, da lei n. 13.089 que institui o Estatuto das Metrópoles (Brasil, 2015) expõe a relevância da pesquisa nessa área.

Este trabalho apresenta resultados parciais de pesquisa sobre configuração espacial em cidades aglomeradas e seu objetivo é analisar os prováveis efeitos da atratividade entre cidades aglomeradas, nas escalas intra e interurbana. Pretende-se responder à seguinte questão: como identificar os efeitos espaciais da atratividade entre cidades considerando atividades complementares, como o caso dos deslocamentos potenciais entre os locais de habitação e os locais de oferta de comércio e serviços?

Para tanto, vai-se utilizar de uma abordagem configuracional (Batty, 2008; Crucitti et al., 2006), que faz uso de modelos urbanos e adota metodologias para representar a cidade como uma rede sócio-espacial, formada por células interconectadas, sendo possível aplicar medidas quantitativas e indicadores de seu desempenho.

0 artigo está organizado em quatro partes, além desta introdução. Inicialmente, apresenta-se um breve quadro teórico de referência incluindo a discussão dos fundamentos das aglomerações e sua relação com a morfologia urbana e os estudos configuracionais. Na sequência apresenta-se a metodologia para o estudo proposto. 0 item seguinte apresenta o estudo empírico e os resultados da análise configuracional. Finalizando o trabalho, apresentam-se algumas conclusões possibilitadas pelo estudo. 


\section{Aglomerações e forma urbana}

Em termos geográficos, as aglomerações urbanas podem ser vistas como produto de intensas relações socioeconômicas entre núcleos urbanos, que emergem através da força de polarização que cada uma dessas localidades apresenta. 0 resultado dessas vinculações é expresso através do surgimento de um novo sistema urbano, que compreende um conjunto de cidades, incluindo a dinâmica formada entre elas (Ultramari \& Moura, 1994).

Enquanto o termo aglomeração urbana tem sido usado para designar de forma mais genérica situações de cidades próximas com intensas relações, o termo região metropolitana pressupõe a existência de uma cidadepolo (metrópole). Ou seja, quando uma das cidades que formam uma aglomeração urbana crescer e se destacar demais, apresentando uma área de influência pelo menos regional, então não se está mais diante de uma aglomeração, mas de uma região metropolitana (Souza, 2008). Existem situações nas quais as vinculações interurbanas acabam se manifestando através da união física dos tecidos urbanos de cidades limítrofes, resultando em uma mancha urbana única das cidades envolvidas que é denominada conurbação (Souza, 2008). Davidovich \& Lima (1975) ao classificarem as aglomerações urbanas brasileiras chamam atenção para esse tipo específico de expressão do fenômeno, denominando-as como aglomerações caracterizadas por um espaço urbanizado predominantemente contínuo.

No Brasil, já há certa tradição de estudos sobre aglomerações urbanas, destacando-se os desenvolvidos pelo Instituto Brasileiro de Geografia e Estatística - IBGE já mencionados, como, por exemplo: as Regiões de Influência das Cidades - REGIC (IBGE, 2007) e o estudo dos Arranjos Populacionais e Concentrações Urbanas do Brasil (IBGE, 2015). No âmbito do Cedeplar/UFMG pode-se mencionar o trabalho de Lemos et al. (2003) sobre a delimitação de polos econômicos e suas áreas de influência e o de Simões \& Amaral (2011) sobre a identificação de redes urbanas policêntricas.

Camagni (2005) reforça a importância das economias de aglomeração e das vantagens que provêm delas, destacando os elementos "invisíveis" (forças e benefícios) que estão na base de um modelo de atividades concentrado, apontando ainda que estes benefícios não ocorrem somente em termos produtivos, mas também em termos administrativos, na individualidade e na vida em sociedade da população, diminuindo os desgastes das atividades diárias (distâncias e tempo), tornando-os mais eficientes. Christaller (1966) foi pioneiro na descrição e análise de paisagens de cidades hierarquizadas, levando em conta fatores como a composição da oferta de bens e serviços especializados presentes em cada cidade e a distância com relação aos consumidores. Fujita et al. (2002) avançaram nessa discussão, refletindo sobre a dinâmica de tal hierarquia regional. Os autores questionam por que as atividades econômicas tendem a se aglomerar em algumas poucas localizações e até que ponto essa concentração é sustentável, ou seja, sob que condições as vantagens criadas por tal concentração são suficientes para mantê-la. Segundo os autores, as respostas a essas questões dependem do equilíbrio entre forças centrípetas, forças que tendem a promover a concentração espacial da população e da atividade econômica, e forças centrífugas, que se opõem a tal concentração. Seus modelos utilizam variáveis como o preço dos produtos, custos de transporte, o tamanho da população e da mão de obra, as quais concorrem para criar paisagens dinâmicas, com diferentes hierarquias de cidades, tais como observadas na realidade.

Nesse sentido, as aglomerações urbanas devem ser entendidas num contexto dinâmico, no qual convivem forças de atração e dispersão que, ao longo do tempo, vão caracterizando as hierarquias regionais de cidades e suas áreas de influência. Também se pode observar que a existência de relações de complementariedade e de proximidade entre núcleos urbanos é significativa no entendimento de aglomeração urbana. Assim, quanto mais próximos os núcleos urbanos se encontram, maior a probabilidade de interação entre eles, da mesma maneira que, quanto maior a relação de complementariedade de usos entre os núcleos urbanos, maiores são as chances de estabelecerem vínculos entre si.

Dentre os estudos que relacionam mais diretamente as aglomerações e a morfologia urbana, foco deste trabalho, está o de Colusso (2015). A autora investiga o processo da dinâmica regional e sua influência sobre as formas urbanas e a estrutura interna das cidades. A metodologia relaciona a interação 
espacial (Wilson, 1971) e os modelos configuracionais de centralidade (Krafta, 1994), considerando aspectos como o tamanho (população) e a posição relativa das cidades na rede regional, o número de conexões viárias, a oferta de atividades atratoras (empregos, serviços, educação etc.).

Já Rigatti (2009) propõe um índice que visa medir a intensidade da conurbação existente entre as partes de um sistema urbano ou regional, utilizando abordagem da Sintaxe Espacial (Hillier \& Hanson, 1984). O índice compara as características morfológicas das partes (subsistemas) com aquelas apresentadas pelo conjunto - a estrutura emergente. Tem como base a medida de integração global (acessibilidade topológica relativa), que é considerada fundamental para capturar aspectos essenciais do funcionamento da estrutura dos leiautes urbanos e as relações existentes entre centralidade morfológica e a distribuição das atividades urbanas e dos padrões de movimento. Já Ugalde (2013) analisa o processo de estruturação espacial da região metropolitana de Porto Alegre procurando examinar a formação de rotas prioritárias de movimento em diferentes escalas, identificando assim sua hierarquia espacial emergente ou potencial. Utiliza a medida configuracional de Escolha, que afere um valor de perpasse ou importância relativa de um espaço nos caminhos mínimos que ligam o sistema espacial.

\section{Estudos configuracionais}

Os Estudos Configuracionais Urbanos se constituem como uma ampla gama de abordagens morfológicas que trabalham de modo sistêmico no desenvolvimento de modelos e medidas de diferenciação espacial, contribuindo para entender a estruturação espacial urbana (Zechlinski, 2013). Inúmeros estudos vêm sendo desenvolvidos nessa área, tais como os de Hillier \& Hanson (1984), Batty (2008), Porta et al. (2009). Nesse entendimento, a estrutura urbana pode ser representada e analisada através de diferentes medidas de centralidade, cujos valores estão correlacionados com vários indicadores de atividade do sistema urbano, tais como presença de pedestres, fluxo de veículos e concentração de atividades comerciais, podendo ser tomada como um indicador de qualificação locacional (Krafta, 1994).

Modelos configuracionais adotam metodologias de desagregação da cidade em componentes (unidades elementares de espaço, atributos espaciais) e suas relações (descrições topológicas, adjacências, centralidade), sendo que a teoria dos grafos fornece a base analítica para o cálculo de diferentes medidas e propriedades da rede urbana. Os modelos assumem a hipótese do caminho mínimo, ou seja, de que as ligações entre células da rede sempre serão feitas pelos caminhos mais curtos. Dessa forma, qualquer cidade exibiria uma diferenciação espacial, ou seja, uma hierarquia na qual algumas células (espaços) se destacam pela sua posição relativa e/ou pelo número de conexões com os demais.

Krafta (1994) propõe a diferenciação pela propriedade espacial da Centralidade, uma medida de hierarquia espacial que busca identificar o papel que cada célula (espaço) do sistema desempenha na conexão possível entre todos os pares de células deste sistema. A medida considera que a tensão gerada por cada par de espaços (produto de seus atributos ou carregamentos) sofrerá uma dissipação, ou seja, será distribuída entre todas as células que fazem parte dos caminhos mínimos, considerando dessa forma o efeito da distância.

Considerando que a Centralidade é função da configuração espacial e do uso do solo, é possível supor o interesse em detectar o efeito de um determinado uso do solo específico sobre a centralidade. Para isso foi desenvolvido o indicador de Polaridade (Krafta, 2014), cujo processamento considera apenas pares origem-destino selecionados. Com esta restrição, apenas os pares que possuam atributos opostos serão considerados no cálculo, resultando numa medida que atribui frações de centralidade a todos os espaços que operam como conectores entre as origens e destinos selecionados. Por exemplo, pode-se calcular a polaridade entre os espaços que possuam o atributo "residências" e os que têm o atributo "comércio varejista". A Polaridade é expressa pela Equação 1:

$$
\operatorname{Pol}_{I i}=\frac{\left(P_{D} \cdot Q_{O}\right)}{[\min ] d_{p q}}
$$


A Polaridade da entidade i na interação I é igual ao carregamento das demandas do espaço P multiplicado pelas ofertas do espaço $Q$ dividido pela distância entre as entidades $\mathrm{p}$ e q.

Sendo:

$P_{l_{l i}}$ : Polaridade do espaço i na interação I;

$P_{D}$ : Carregamento das demandas de um espaço qualquer $\mathrm{P}$;

$Q_{O}$ : Carregamento das ofertas de um espaço qualquer Q;

$[\min ] d_{p q}$ : Caminho mínimo entre os espaços $\mathrm{P}$ e Q.

A Polaridade absoluta de cada entidade espacial será expressa pela Equação 2:

$\operatorname{Pol}_{A i}=\sum_{i=1}^{i j} \operatorname{Pol}_{I i}$

A Polaridade absoluta da entidade $i$ é igual ao somatório das polaridades da entidade $i$ em todas as interações I, de $i$ a $j$, sendo o primeiro $i$ igual a 1 .

Sendo:

$\mathrm{Pol}_{A i}$ : Polaridade absoluta do espaço i;

$\mathrm{Pol}_{I i}$ : Polaridade do espaço i na interação I.

A Polaridade é uma medida de atratividade relativa, que permite inferir um determinado tipo de complementaridade entre diferentes unidades do espaço urbano. Essa complementaridade funcional tende a alterar o "[...] status dos espaços e interfere na escolha de destinações preferenciais realizadas pelos usuários [...]" (Krafta, 2014, p. 153).

No caso do presente trabalho, a Polaridade vai representar a importância que determinados espaços assumem na relação entre as atividades residenciais e as de consumo (comércio e serviços) numa aglomeração urbana. Nesse sentido, podem-se identificar os espaços mais tensionados nos deslocamentos potenciais entre tais atividades, fornecendo uma primeira medida do impacto dessas relações funcionais sobre o território.

No que se refere às atividades de comércio varejista e serviços, sabe-se que sua distribuição espacial e composição de tipos não é homogênea no território, ao contrário, apresenta-se em concentrações lineares e polos de diferentes tamanhos e especializações (Berry, 1967). Tal distribuição é complexa e envolve fatores ligados à demanda (presença de população com capacidade de consumo, hábitos de gasto etc.), à oferta (tipos de organizações varejistas, competição etc.) e ao sistema urbano (acessibilidade, centralidade) (Maraschin, 2013). É importante salientar que o presente trabalho não pretende aprofundar tais aspectos mas tomar a localização dos estabelecimentos varejistas e de serviços como um dado de partida para então avaliar a sua relação potencial com as localizações residenciais, identificando alguns impactos dessa relação na configuração espacial da aglomeração.

\section{Metodologia do estudo}

O estudo empírico selecionado para este trabalho é um setor da Região Metropolitana da Serra Gaúcha (RMSG), no nordeste do Estado. A seleção inclui três cidades: Bento Gonçalves, Garibaldi e Carlos Barbosa, cujas manchas urbanas estão bastante próximas, mantendo uma distância relativa de Caxias do Sul (principal polo) e das demais cidades da RMSG. As cidades selecionadas possuem uma forte interação funcional entre si (empregos, serviços, estudos etc.) e também apresentam algumas áreas em conurbação. Dessa forma, sem desconhecer a possível existência de outras relações funcionais com o restante da Região, delimita-se o foco do presente estudo nessas três cidades como uma aglomeração urbana.

Conforme mencionado, este trabalho analisa as aglomerações urbanas a partir de uma abordagem configuracional, que permite articular, de forma sistêmica, variáveis relativas ao espaço urbano (rede de vias), à demanda (população) e à oferta (neste caso, os estabelecimentos comerciais e de serviços). 
A medida de Polaridade é adotada como um indicador de atratividade relativa e será calculada para duas situações (ou cenários): as cidades isoladas e as cidades como um sistema espacial único. A comparação destes cenários permitirá discutir possíveis efeitos da relação funcional residências-consumo, quando a aglomeração passa a ser considerada.

A modelagem do sistema em estudo envolveu inicialmente a sua representação espacial. A base espacial contém a rede de espaços-canal disponíveis no sistema para compor os percursos ligando os pares de localizações. Neste trabalho, a base espacial utilizada é uma representação das cidades por trechos de vias (espaço geográfico contido entre duas esquinas). A Figura 1 apresenta o sistema espacial da aglomeração e exemplifica o processo de representação espacial por trechos de vias.

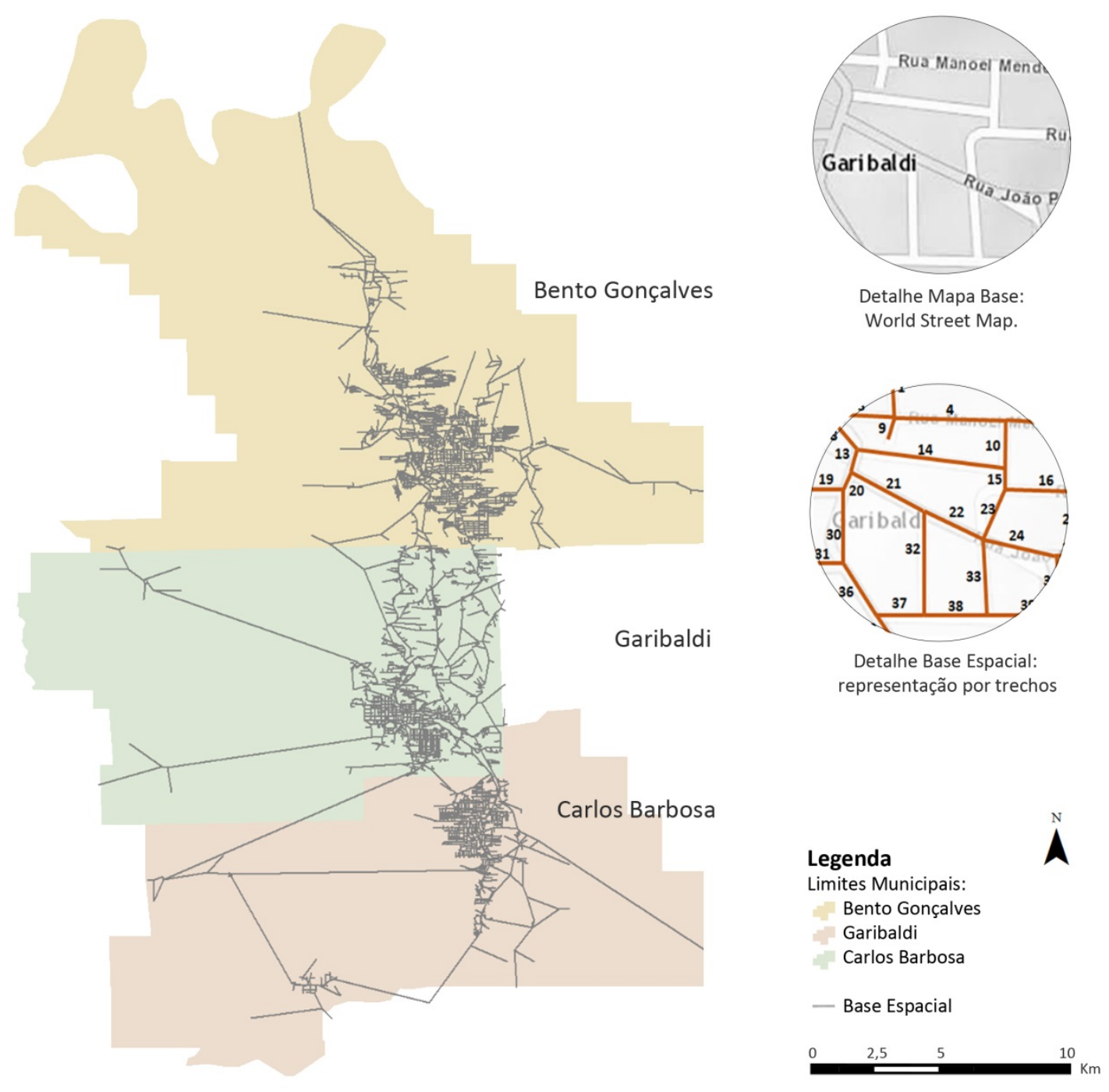

Figura 1 - Representação espacial da aglomeração por trechos de vias (esq.) e detalhe da representação espacial (dir.). Fonte: autores com base em World Street Map (ESRI ArcGIS, 2013).

A escolha desta representação espacial se deu em função de permitir elevado nível de desagregação e detalhe do sistema urbano, o que é importante quando se trata da localização comercial. o processo de elaboração da representação espacial se dá através do desenho dos trechos sobre os mapas disponibilizados pelas administrações dos municípios, complementados pelo basemap World Street Map do software ArcMap, versão 10.2 (ESRI ArcGIS, 2013). A base espacial da aglomeração totalizou 
6.634 trechos de vias considerando as cidades em conjunto, sendo que Bento Gonçalves detém a maior quantidade de trechos (3.077), seguida por Garibaldi (2.219) e Carlos Barbosa (1.338).

Com a base espacial finalizada, foram organizados os dados empíricos para compor os atributos funcionais de cada espaço (trecho) necessários ao cálculo dos indicadores espaciais. Os dados relativos à demanda, ou seja, os potenciais consumidores das atividades de comércio e serviços, correspondem à população residente em cada um dos trechos das cidades. Esse dado foi estimado através do Censo de 2010 do IBGE (2012) (arquivo Básico, variável V002) referente à quantidade de moradores por setor censitário. O IBGE também disponibiliza a malha digital destes setores no formato shapefile, que foi importada para o mesmo ambiente SIG. A população total de cada setor censitário foi igualmente distribuída entre os trechos de vias incluídos na sua abrangência.

Já as ofertas se referem à quantidade de estabelecimentos comerciais varejistas e de serviços presentes em cada trecho. Os dados foram obtidos junto às Secretarias da Fazenda de cada município, e constam de uma lista de atividades e seus endereços relativos ao ano de 2015. As ofertas foram distribuídas no sistema espacial através da identificação do trecho em que elas incidem, demarcados através dos endereços informados, geocodificados a partir do aplicativo experimental Google Fusion Tables (2018) que se encontra disponível on-line e georreferencia endereços a partir de uma planilha do Microsoft Excel. Assim, uma tabela no formato .xls é importada para o aplicativo e este gera um mapa com a localização dos usos. De um total de 13.664 estabelecimentos constantes na relação obtida junto às Secretarias da Fazenda Municipais, 635 não puderam ser localizados por problemas nos endereços ou duplicidade de registro, resultando 13.029 estabelecimentos localizados e uma perda de $4,65 \%$ dos dados.

O mapa com a localização dos estabelecimentos foi exportado em formato $\mathrm{kml}$, manuseado no software Google Earth e posteriormente na plataforma SIG, na qual as informações de ofertas foram alocadas a cada trecho através do comando near table, que identifica o trecho mais próximo aos usos georreferenciados.

Após esta etapa de preparação, os atributos referentes à quantidade de população e de atividades foram organizados em tabelas na plataforma SIG (formato.xml) e importados para o software Medidas Urbanas (Polidori etal., 2001). Este software é uma ferramenta utilizada para o processamento de medidas configuracionais a partir da representação espacial (arquivo.dxf) e da importação de tabelas contendo os atributos dos espaços que formam o sistema. 0 software Medidas Urbanas permite que as atividades de oferta sejam diferenciadas por ponderações (pesos específicos) de forma a representar diferentes capacidades de atração de população. Dada a natureza das atividades comerciais, geralmente atribui-se um peso de atratividade maior do que para os serviços. Neste caso, devido a diferenças de critérios de classificação destas atividades entre as Secretarias da Fazenda dos três municípios, optou-se por deixar ambas com a mesma ponderação (peso 10). Para o caso dos shoppings centers, foi estimada uma ponderação proporcional, que considerou a quantidade de lojas e de vagas de estacionamento em cada empreendimento, resultando o Shopping L'América com peso 750 e o Shopping Bento Gonçalves com peso 700.

Para o processamento do cálculo das distâncias foi utilizada a distância geométrica (métrica) entre cada par de trechos. Testes comparativos preliminares mostraram que o processamento topológico tendia a identificar como menores caminhos longas estradas vicinais pouco utilizadas, por vezes sem pavimentação, em topografias bastante acidentadas, as quais, no entanto, vencem distâncias com poucos passos topológicos. Já o processamento geométrico conseguiu captar melhor o papel de vias mais intraurbanas e da BR 470, sendo mais plausível a partir do conhecimento empírico das cidades.

A fim de comparar os resultados do modelo de Polaridade nos dois cenários, foram utilizados os valores normalizados, também calculados pelo software, permitindo a comparação de sistemas com tamanhos diferentes.

Os resultados dos modelos processados pelo software são disponibilizados através de mapas e/ou tabelas, que podem ser exploradas de maneira comparativa, por quantificações e análises visuais. A Figura 2 resume as etapas metodológicas da análise empírica. As linhas amarelas representam a preparação dos dados de entrada para o modelo e as linhas verdes o pós-processamento dos resultados modelados da Polaridade. 


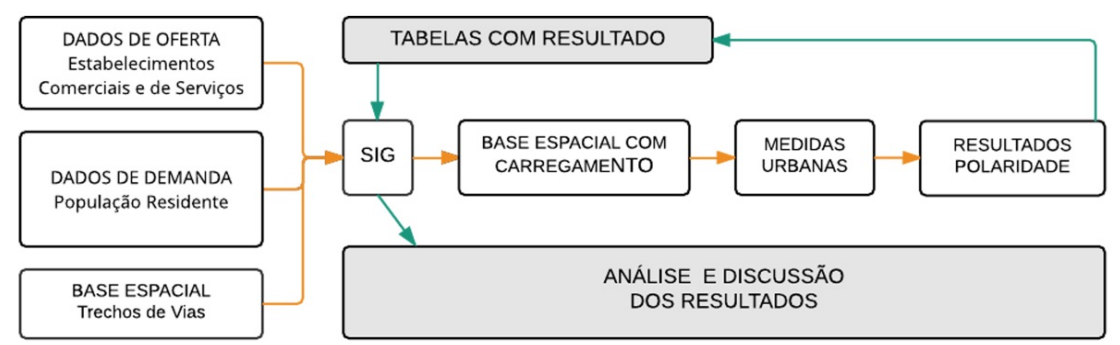

Figura 2 - Esquema das etapas metodológicas da análise espacial. Fonte: autores.

A fim de parametrizar a análise dos resultados para sistemas que possuem diferentes tamanhos (quantidade de trechos), foi adotado o método de análise proposto por Jiang (2008) que, observando a alta hierarquia existente na conectividade dos sistemas, verifica uma relação de $80 / 20$, dividindo o sistema a partir de três percentuais, $80 \%, 20 \%$ e $1 \%$, que correspondem às vias mal conectadas, vias bem conectadas e vias extremamente bem conectadas, respectivamente. Assim, nesse trabalho, editou-se uma listagem com a classificação em ordem decrescente dos valores de Polaridade de cada trecho, diferenciando as seguintes percentagens: $1 \%$ dos trechos com maiores valores (altíssima Polaridade) e entre $1 \%$ e $20 \%$ dos trechos com maiores valores (alta Polaridade).

\section{Estudo empírico}

\section{Contextualização}

As cidades selecionadas como objeto de estudo encontram-se na Região Metropolitana da Serra Gaúcha, localizada no Sudoeste do Estado do Rio Grande do Sul (Figura 3).
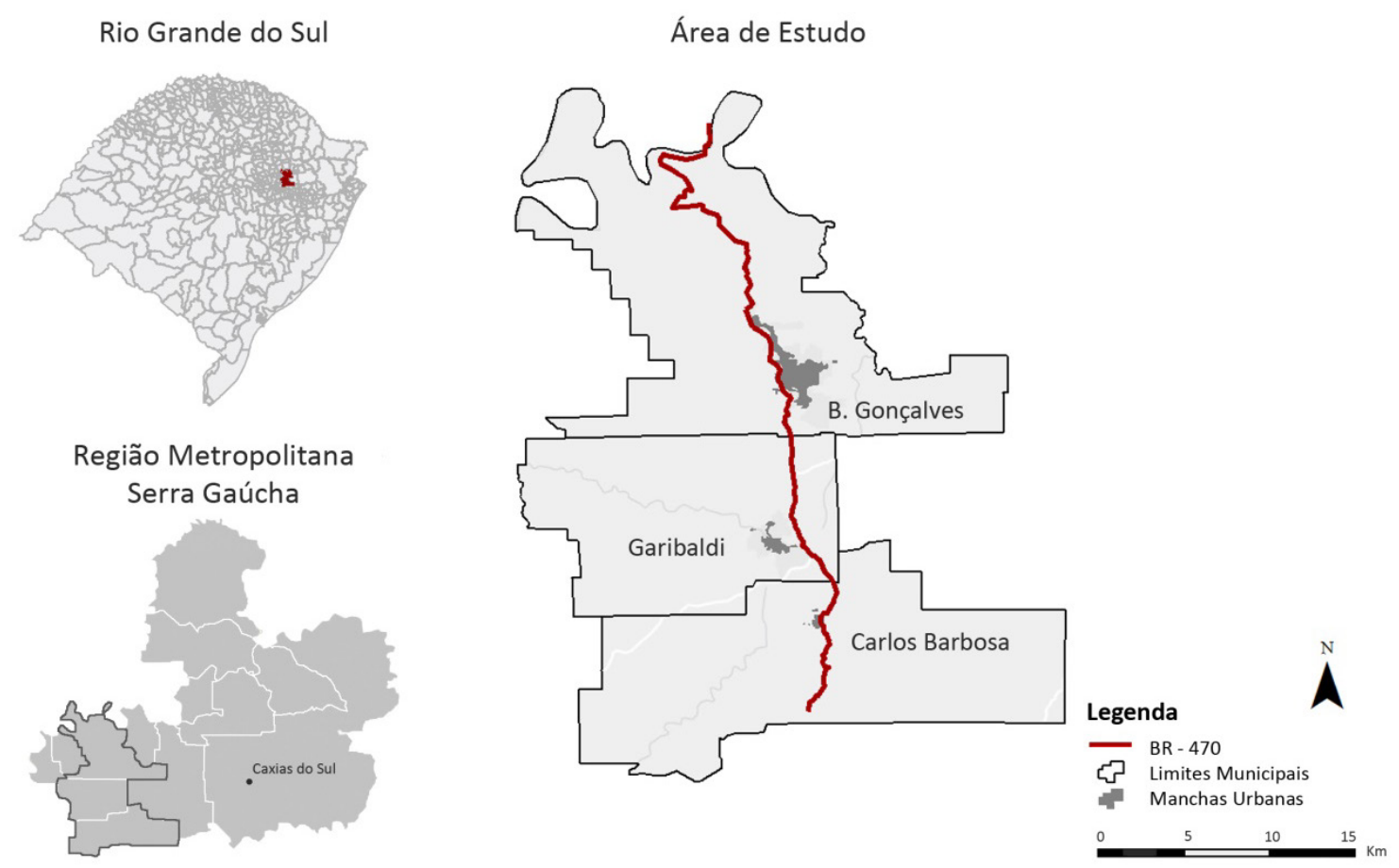

Figura 3 - Localização geral da área de estudo. Fonte: autores, com base cartográfica do IBGE (2012). 
Esta Região foi instituída pela Lei Complementar n. 14.293, de agosto de $2013^{1}$ e corresponde aos municípios pertencentes à antiga Aglomeração Urbana do Nordeste (AUNe), criada em 1994, acrescida dos municípios de Antônio Prado, Ipê e Pinto Bandeira.

Em termos econômicos, a RMSG se destaca no âmbito estadual pela concentração de grandes indústrias, enquanto a nível nacional e internacional sua relevância se dá principalmente pelo setor da enocultura.

Tais municipios surgiram a partir de uma série de colonizações, principalmente a italiana, que ocorreram no Estado do Rio Grande do Sul durante o século XVII e até hoje mantêm suas tradições, principalmente no que diz respeito ao cultivo da uva e à fabricação de vinhos e espumantes. As três cidades apresentam alto nível de desenvolvimento, medido pelas suas classificações de IDHM (PNUD,

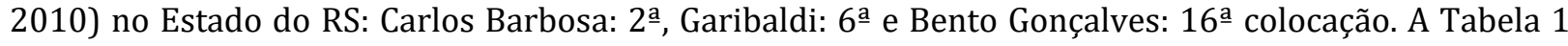
apresenta dados populacionais das três cidades.

Tabela 1. Dados populacionais dos municípios

\begin{tabular}{cccccc}
\hline Local & $\mathbf{1 9 9 1}$ & $\mathbf{2 0 0 0}$ & $\mathbf{2 0 1 0}$ & $\mathbf{2 0 1 6}$ & $\begin{array}{c}\text { Crescimento } \\
\mathbf{1 9 9 1 - 2 0 1 6}\end{array}$ \\
\hline B. Gonçalves & 78.643 & 91.486 & 107.278 & 114.203 & $45 \%$ \\
Garibaldi & 25.926 & 28.337 & 30.689 & 33.384 & $29 \%$ \\
C. Barbosa & 15.921 & 20.519 & 25.192 & 27.835 & $75 \%$ \\
RS & 9.138 .670 & 10.187 .798 & 10.693 .929 & 11.286 .500 & $23 \%$ \\
Brasil & 146.825 .475 & 169.799 .170 & 190.755 .799 & 207.381 .432 & $41 \%$ \\
\hline
\end{tabular}

Fonte: IBGE $(2012,2014)$.

Verifica-se que os três municípios vêm apresentando expressivos dados de crescimento populacional nos últimos anos, ficando acima do percentual de crescimento do Estado nesse mesmo período. Apesar de serem cidades fortemente industrializadas, o setor de serviços tem muita importância econômica, com destaque para Bento Gonçalves, na qual 62\% do seu VAB (Valor Adicionado Bruto) provêm de serviços (Tabela 2).

Tabela 2 - Dados econômicos dos municípios

\begin{tabular}{cccccccc}
\hline \multirow{2}{*}{ Local } & \multirow{2}{*}{ PIB per capita } & \multicolumn{5}{c}{ VAB (Valor Adicionado Bruto) } \\
\cline { 3 - 7 } & & Agropecuária & $\%$ & Indústria & $\%$ & Serviços & $\%$ \\
\hline B. Gonçalves & $32.036,33$ & 81.459 & 2,7 & 1.030 .599 & 34,9 & 1.844 .225 & 62,4 \\
Garibaldi & $37.783,45$ & 51.968 & 5,2 & 462.032 & 46,2 & 486.839 & 48,6 \\
C. Barbosa & $39.427,29$ & 65.236 & 7,9 & 379.281 & 45,9 & 381.244 & 46,2 \\
\hline
\end{tabular}

Fonte: IBGE (2012); valores em reais.

Analisando mais especificamente as atividades de comércio e serviços, foco deste trabalho, a Tabela 3 mostra a distribuição dos estabelecimentos nos diferentes municípios.

Tabela 3 - Distribuição da população e da quantidade de estabelecimentos terciários

\begin{tabular}{|c|c|c|c|c|c|c|c|}
\hline \multirow{2}{*}{ Tipo } & \multicolumn{2}{|c|}{ Bento Gonçalves } & \multicolumn{2}{|c|}{ Garibaldi } & \multicolumn{2}{|c|}{ Carlos Barbosa } & \multirow{2}{*}{$\begin{array}{c}\text { Quant. } \\
\text { total }\end{array}$} \\
\hline & Quant. & $\%$ & Quant. & $\%$ & Quant. & $\%$ & \\
\hline \multirow{3}{*}{$\begin{array}{c}\text { População } \\
\text { Estabelec. varejistas e } \\
\text { de serviços } \\
\text { Shopping centers }\end{array}$} & 114.203 & 65 & 33.384 & $19 \%$ & 27.835 & 16 & 175.422 \\
\hline & 9.198 & 67 & 2.555 & $18 \%$ & 1.909 & 15 & 13.662 \\
\hline & 02 & 100 & - & - & - & - & 02 \\
\hline
\end{tabular}

Fonte: autores com base em IBGE (2014) e cadastros das Secretarias Municipais da Fazenda de Bento Gonçalves, Garibaldi e Carlos Barbosa, ano 2015.

\footnotetext{
${ }^{1}$ A METROPLAN (Fundação Estadual de Planejamento Metropolitano e Regional) emitiu um parecer em 2013 manifestando-se contrária à mudança da área de Aglomeração Urbana para Região Metropolitana, apoiada em uma análise das variáveis macroeconômicas e espaciais da AUNe (METROPLAN, 2013).
} 
É possível observar que Bento Gonçalves detém aproximadamente dois terços do total de população e de estabelecimentos comerciais e de serviços desta aglomeração. Além disso, somente Bento Gonçalves possui empreendimentos do tipo shopping center, o Shopping Bento Gonçalves ( $7.500 \mathrm{~m}^{2} \mathrm{ABL}, 71$ lojas) e o L'America Shopping Center (2.300 $\mathrm{m}^{2} \mathrm{ABL}, 42$ lojas), sendo classificados como de pequeno porte, segundo critérios da ABRASCE (2017) (Associação Brasileira de Shopping Centers). Os dados demonstram uma grande diferença de hierarquia entre as três cidades no que se refere à distribuição da população (demanda) e das atividades terciárias (oferta). No próximo item, busca-se simular a interação entre essas atividades, mediadas pelo espaço urbano, visando identificar alguns efeitos espaciais.

\section{Resultados e discussão}

Este item apresenta os resultados do cálculo da Polaridade para os diferentes cenários de estudo. A Figura 4 apresenta inicialmente o sistema espacial das três cidades, destacando as áreas de seus centros históricos. É possível identificar loteamentos mais regulares que ocupam áreas mais planas, articulados entre si por algumas vias que vencem os desníveis. As manchas urbanas das três cidades se situam em áreas relativamente mais planas. Além da rodovia principal que une as cidades, observam-se inúmeras estradas secundárias presentes nas zonas rurais.

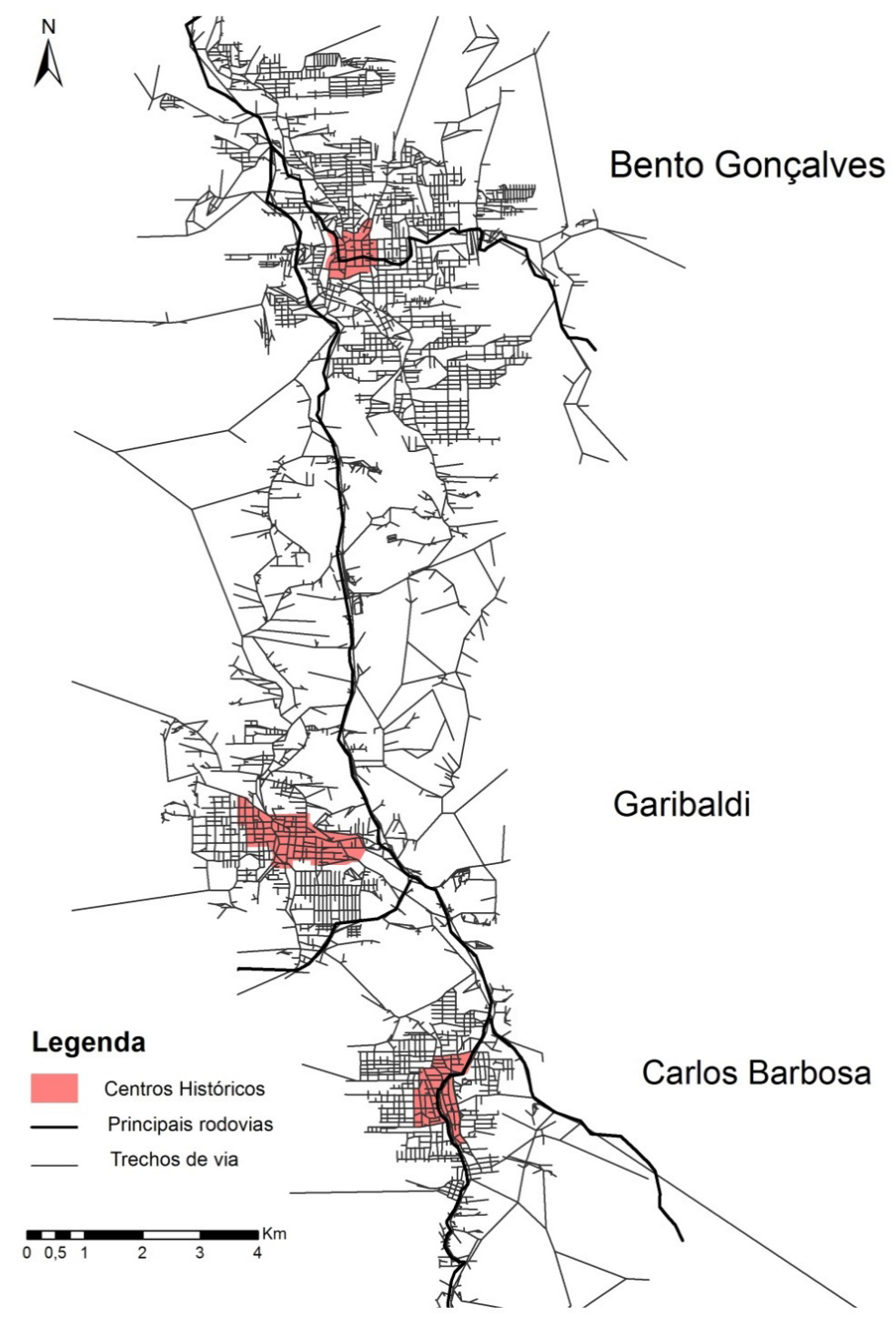

Figura 4 - Sistema espacial das três cidades com destaque para os seus centros históricos. 
A Figura 5 apresenta a comparação dos resultados para os dois cenários básicos: as cidades em separado e a aglomeração como um sistema espacial único.

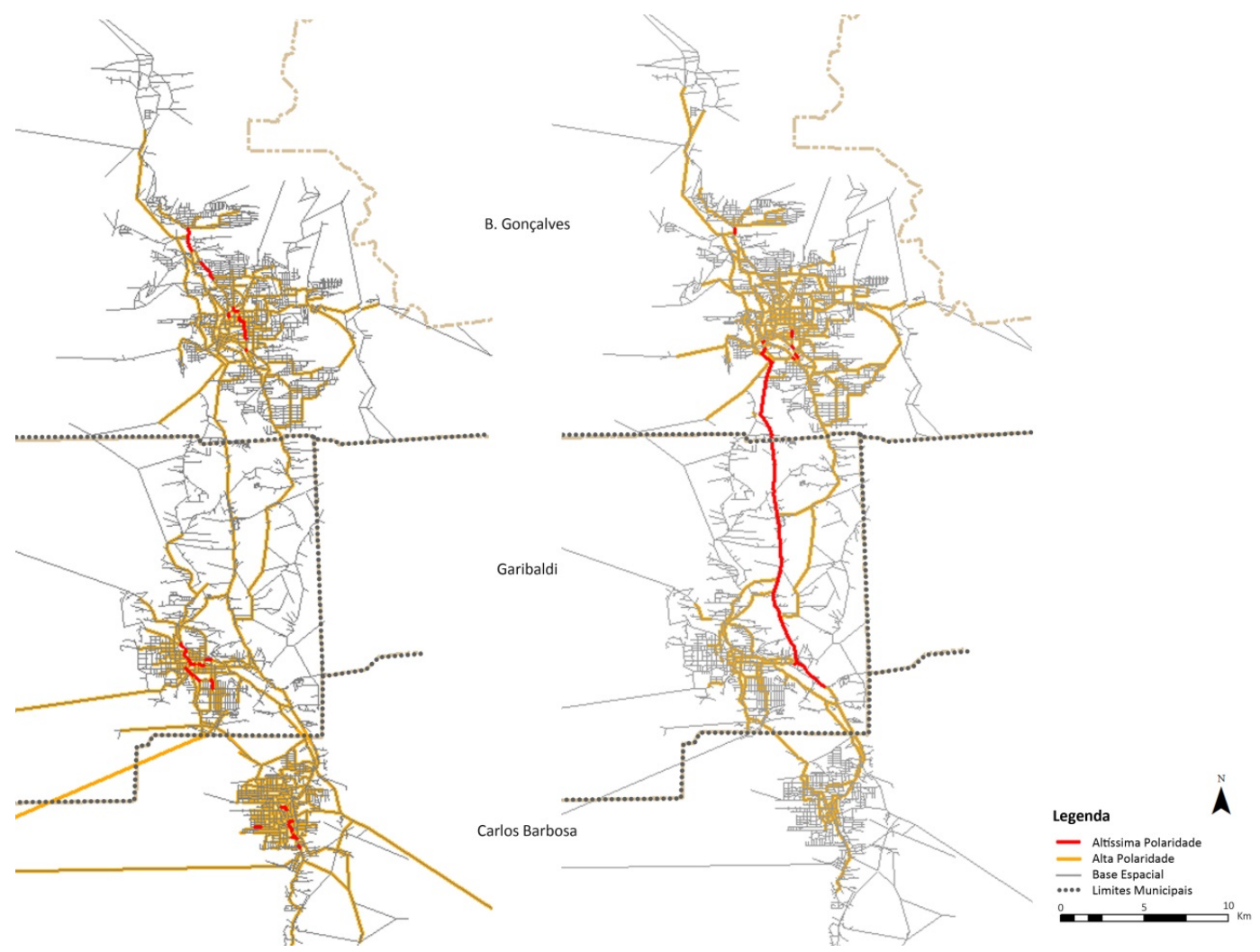

Figura 5 - Trechos com maiores valores de Polaridade (1\% e 20\%) na relação população total x atividades de comércio e serviços considerando as cidades em separado (esquerda) e o conjunto da aglomeração

(direita). Fonte: autores.

No cenário das cidades isoladas, os valores de altíssima Polaridade (1\%) se localizam nos trechos pertencentes às áreas centrais (centros históricos) e seu entorno. Tais trechos possuem, simultaneamente, atributos de centralidade na malha e concentração da maior parte das atividades de comércio e serviços de cada cidade.

Quando a aglomeração é considerada, evidencia-se que a BR-470, rodovia que conecta as três cidades de norte a sul, forma um eixo contínuo de altíssima Polaridade ao longo do sistema como um todo. Em Bento Gonçalves, esse eixo se conecta com a malha intraurbana, já no caso de Garibaldi apenas a tangencia.

A Tabela 4 mostra os resultados quantitativos sobre os trechos mais polarizados nos dois cenários. Verifica-se que, nas cidades aglomeradas, os trechos de altíssima Polaridade tendem a se concentrar em Garibaldi (74\%), cidade que está localizada no centro da aglomeração e tem, portanto, as distâncias minimizadas para as demais.

Tabela 4 - Resultados da Polaridade em quantidade de trechos mais polarizados (1\% e 20\%) nos dois cenários

\begin{tabular}{|c|c|c|c|c|c|c|}
\hline \multirow{3}{*}{$\begin{array}{l}\text { Cenários } \\
\text { Cidades }\end{array}$} & \multicolumn{2}{|c|}{ Cidades isoladas } & \multicolumn{4}{|c|}{ Cidades aglomeradas } \\
\hline & \multirow[b]{2}{*}{$1 \%$} & \multirow[b]{2}{*}{$20 \%$} & \multicolumn{2}{|c|}{ Até $1 \%$} & \multicolumn{2}{|c|}{ Entre $1 \%$ e $20 \%$} \\
\hline & & & $\begin{array}{l}\text { Quantidade } \\
\text { trechos }\end{array}$ & $\%$ do total & Quantidade trechos & $\%$ do total \\
\hline B. Gonçalves & 31 & 585 & 17 & 26 & 803 & 60 \\
\hline Garibaldi & 22 & 444 & 49 & 74 & 357 & 27 \\
\hline C. Barbosa & 13 & 268 & 0 & 0 & 167 & 13 \\
\hline \multicolumn{3}{|c|}{ Total } & 66 & 100 & 1327 & 100 \\
\hline
\end{tabular}

Fonte: autores, através dos mapas temáticos obtidos no processamento da medida de Polaridade. 
Bento Gonçalves aparece em segunda colocação, com 26\% dos trechos com altíssima Polaridade, e Carlos Barbosa não apresenta nenhum trecho nesta condição. Outro aspecto é que Bento Gonçalves e Carlos Barbosa perdem trechos em posições de altíssima centralidade em favor de Garibaldi quando os dois cenários são comparados.

Quanto aos resultados de alta Polaridade (valores entre 1\% e 20\%), verifica-se que Bento Gonçalves é dominante, concentrando $60 \%$ do total de trechos com altos valores no cenário da aglomeração. Isso indica que a localização central de Garibaldi na aglomeração não foi capaz de sustentar a maior hierarquia. Bento Gonçalves é o maior sistema espacial da aglomeração, possui a maior quantidade de demanda (população) e de ofertas (estabelecimentos de comércio e serviços) e tal fato deve estar compensando sua posição mais excêntrica na aglomeração, junto à extremidade norte. A comparação dos dois cenários com relação aos altos valores de Polaridade mostrou uma forte alteração na localização dos trechos. Verificou-se que tanto Garibaldi como Carlos Barbosa perdem trechos de alta Polaridade em favor de Bento Gonçalves.

Os resultados mostram que os espaços que possuem mais relevância (centralidade) para comércio e serviços a nível intraurbano se alteram quando a aglomeração é considerada. Entendendo que a medida de Polaridade pode ser considerada um indicador de fluxos (pessoas, mercadorias, tráfego veicular etc.), a BR-470 tenderia a receber os maiores volumes de fluxo oriundo dos deslocamentos de potenciais usuários para as atividades de consumo.

Bento Gonçalves, quando vista individualmente, apresenta predominantemente os trechos mais polarizados distribuídos de modo linear na direção norte-sul, correspondendo às vias consideradas como estruturadoras pelo Plano Diretor municipal. Tais vias são consideradas de média e alta fluidez, de modo que são próprias para o transporte coletivo, para o tráfego geral e de cargas (Bento Gonçalves, 2006), sendo apontadas pelo plano local como relevantes para a mobilidade urbana da cidade, correspondendo às potencialidades verificadas na análise.

A fim de analisar melhor as alterações intraurbanas provocadas pela aglomeração, selecionou-se as cidades de Bento Gonçalves e Garibaldi e procedeu-se a uma ampliação das suas áreas urbanas, conforme mostra a Figura 6.
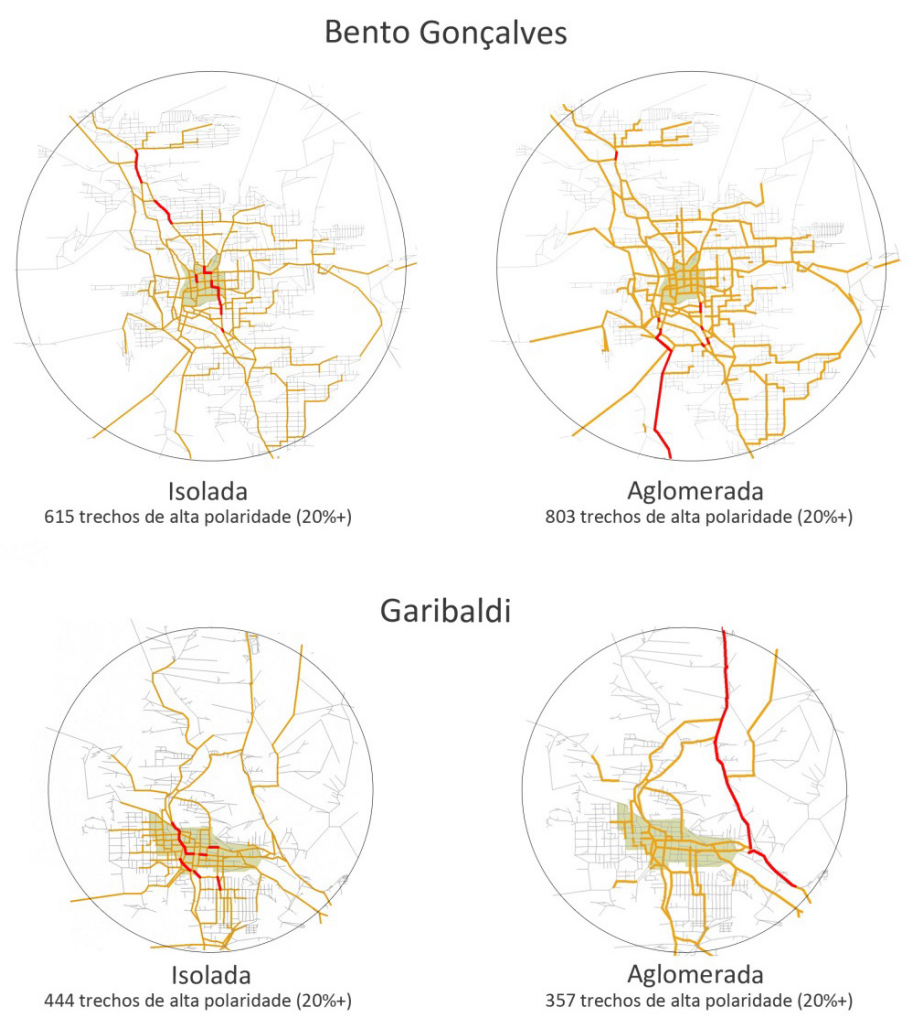

Garibaldi

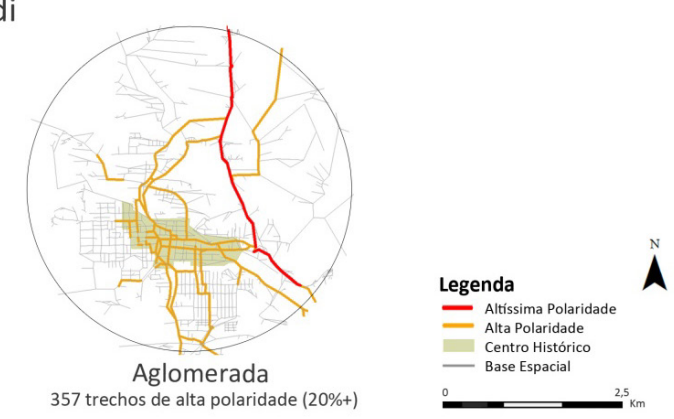

Figura 6 - Comparativo dos resultados da Polaridade nas áreas intraurbanas de Bento Gonçalves e Garibaldi nos dois cenários. Fonte: autores. 
Observa-se que, no caso de Bento Gonçalves, o cenário da aglomeração implicou numa perda de trechos com valores de altíssima Polaridade e num deslocamento desses trechos mais ao sul, na direção da aglomeração. No entanto, em ambos os cenários verifica-se a presença de trechos de altíssima Polaridade no interior da malha urbana. Outro aspecto importante é que configuracionalmente o centro histórico de Bento Gonçalves integra esse núcleo de espaços com papel importante na relação residência-consumo para toda a aglomeração. Isso aponta um potencial de vitalidade para este centro do ponto de vista das atividades comerciais.

No caso de Garibaldi, a Polaridade se altera de forma mais significativa na comparação dos dois cenários intraurbanos. Conforme visto, o cenário da aglomeração mostrou um aumento da quantidade de trechos com altíssima Polaridade, mas esses trechos se localizam na rodovia que une as três cidades. Sua área interna, de maior ocupação e densidade, perde importância na relação residência-consumo, do ponto de vista da aglomeração. Também o centro histórico de Garibaldi apresentou um enfraquecimento de seu desempenho configuracional no cenário da aglomeração, fato que explicita um limite nos tipos e portes das atividades comerciais que tendem a se localizar no centro. Em outras palavras, o comércio que se localiza no centro de Garibaldi se relaciona à população daquela cidade, tendo limitadas condições de competir pelos consumidores da região. Esta constatação também pode ser estendida para o caso de Carlos Barbosa, que não consta da Figura 6. Esta cidade também perde importância na relação habitação-consumo no cenário da aglomeração, apontando para uma abrangência local das atividades terciárias presentes no seu centro histórico.

Na sequência são analisadas outras características morfológicas das cidades que podem auxiliar a compreensão dos resultados. A Tabela 5 mostra algumas características do sistema espacial da aglomeração, em termos de distâncias e conectividades. Verifica-se a posição mais distante de Bento Gonçalves na aglomeração (em linha reta e por rodovias e vias urbanas), no entanto a cidade tem mais conexões com Garibaldi do que esta tem com Carlos Barbosa.

Tabela 5 - Distâncias entre áreas urbanizadas e número de conexões (rodovias e vias urbanas) das cidades estudadas

\begin{tabular}{cccc}
\hline Cidades & Número de & \multicolumn{2}{c}{ Distâncias entre áreas urbanizadas } \\
\cline { 3 - 4 } & conexões & Em linha reta $\mathbf{( k m )}$ & Por rodovias $(\mathbf{k m})$ \\
\hline B. Gonçalves-Garibaldi & 4 & 4,765 & 6.88 \\
Garibaldi-C. Barbosa & 3 & 0,361 & 0.58 \\
\hline
\end{tabular}

Fonte: autores, a partir dos dados da Metroplan (2013).

A densidade de trechos (trechos $/ \mathrm{km}^{2}$ ) é um indicador relacionado à escala da malha viária, ou seja, uma alta densidade de trechos indica a presença de mais ruas, quadras menores e mais alternativas de caminhos mínimos. A Figura 7 mostra que Bento Gonçalves apresenta a maior densidade de trechos, considerando as duas maiores classes. Carlos Barbosa aparece em segundo lugar e Garibaldi tem as menores densidades de trechos. Cabe destacar que a porção norte de Garibaldi apresenta uma malha viária bastante fragmentada em função da topografia acidentada, limitando as possibilidades de conexões na direção de Bento Gonçalves. 


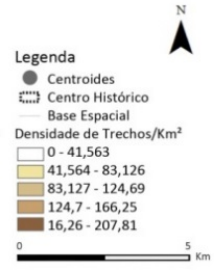

Figura 7 - Densidade de trechos (trechos/ $\mathrm{km}^{2}$ ). Fonte: autores.

Tais deformações no traçado viário implicam em acréscimo das distâncias e a centralidade tende a perder força. Além disso, ruas com alta declividade tendem a desestimular o movimento de pedestres e, de maneira geral, não são favoráveis à localização de comércio. Estudos vêm mostrando que o comércio tende a se localizar ao longo das vias mais acessíveis (Hillier et al., 1993) e em ruas com alto grau de conectividade à sua vizinhança (Hillier, 1999). A Tabela 6 apresenta a conectividade média dos trechos (número médio de ligações de cada trecho).

Tabela 6 - Conectividade média dos trechos de via nas três cidades

\begin{tabular}{cc}
\hline Cidade & $\begin{array}{c}\text { Conectividade dos trechos } \\
\text { (média) }\end{array}$ \\
\hline Bento Gonçalves & 4,19 \\
Garibaldi & 3,90 \\
Carlos Barbosa & 4,21 \\
\hline
\end{tabular}

Fonte: autores.

A Tabela 6 confirma que a rede viária de Garibaldi apresenta uma conectividade média inferior às demais. Assim, sua menor densidade de trechos está associada a uma menor conectividade média dos trechos, criando, na escala local, uma condição de maior isolamento, mesmo Garibaldi ocupando a localização central no conjunto das três cidades.

\section{Considerações finais}

A análise realizada permitiu identificar efeitos espaciais oriundos da atratividade residência-consumo em dois cenários diferentes: as cidades isoladas e o sistema das três cidades aglomeradas. A metodologia foi baseada em modelagem urbana, possibilitando quantificar as alterações ocorridas nestes cenários. A medida configuracional de Polaridade foi utilizada neste estudo como um indicador da hierarquia 
espacial originada pelos deslocamentos potenciais entre os locais de habitação e os locais de oferta de comércio e serviços. Verificou-se que os trechos mais polarizados se alteraram nos cenários considerados, indicando que os caminhos mínimos que tencionam os pares de atividades complementares entre si variam quando a aglomeração urbana passa a ser considerada. A metodologia possibilitou descrever a maior hierarquia configuracional que Bento Gonçalves assume na relação habitação-consumo no cenário da aglomeração. Também foi analisada a situação específica de Garibaldi, que, apesar de sua localização central no conjunto das três cidades, perdeu desempenho no cenário da aglomeração. 0 trabalho também incluiu na discussão alguns fatores da forma urbana que podem estar associados ao desempenho de Garibaldi, entre eles a menor densidade de trechos e a menor conectividade média dos trechos.

Os resultados demonstram o potencial de a metodologia descrever de forma sistêmica e desagregada a atratividade de cada localização urbana (trecho de via) às ofertas de comércios e serviços. Deve-se destacar que a metodologia proposta também permite calcular diferentes Polaridades, a partir da desagregação dos dados de oferta e demanda. Pelo lado da população, esta pode ser classificada por estratos de renda, faixa etária etc.; pelo lado da oferta de consumo, podem ser considerados subconjuntos dos estabelecimentos, tais como supermercados, shopping centers, lojas de rua, serviços etc. Considerando que existe um diferencial na capacidade de atração entre estes diferentes tipos de estabelecimentos varejistas, novos estudos podem utilizar indicadores de atratividade (faturamento, área construída, número de funcionários etc.) a fim de discriminar suas prováveis atratividades sobre a população consumidora. Limitações no banco de dados obtido para o presente estudo não permitiram classificar as atividades terciárias e definir ponderações diferenciadas a cada categoria.

Outro aspecto interessante é que os atributos alocados a cada espaço (demanda e atratores) podem ser identificados como pertencentes a cada uma das três cidades, permitindo gerar outros cenários com diferentes medidas de Polaridade. Por exemplo, pode-se calcular a Polaridade da oferta de comércio e serviços presentes em toda a aglomeração com relação apenas à população de uma das cidades. Essas diferentes Polaridades não foram testadas neste trabalho, mas colocam-se como possibilidades de futuros estudos, contribuindo para identificar efeitos da aglomeração para situações específicas.

Este trabalho explorou as relações habitação-consumo entre cidades aglomeradas, no entanto a metodologia pode ser aplicada para analisar outras relações funcionais, como a atratividade para os empregos e os locais de estudo. Tais relações sócio-espaciais são mais sistemáticas e estruturadas, sendo que o cálculo de diferentes Polaridades funcionais pode contribuir para uma avaliação mais ampla dos efeitos da aglomeração.

A metodologia proposta neste trabalho implicou em algumas simplificações, por exemplo, apenas a população residente foi considerada na relação com o consumo. Novos estudos poderiam incluir os locais de emprego como origem de viagens para consumo, tornando a análise mais realista.

Uma virtude da metodologia aqui apresentada é o fato de ser sistêmica, possibilitando a simulação de cenários alternativos para calcular Polaridade. Por exemplo, podem ser simuladas a implantação de novos estabelecimentos varejistas, a abertura de novas vias, o surgimento de novos bairros residenciais, e verificar-se seu impacto na Polaridade de cada cidade e da aglomeração. Também, na decisão de aprovar a implantação de um novo equipamento urbano, a análise comparativa da Polaridade (atual x proposta) poderia apontar o provável "estresse" decorrente sobre o sistema viário existente. Tal informação pode subsidiar o poder público e a comunidade acerca da necessidade de mitigar impactos, alargar ou abrir novas vias, estender transporte coletivo etc. Esta capacidade da metodologia de gerar cenários alternativos e avaliar impactos é um potencial importante na direção do desenvolvimento de sistemas de suporte à decisão.

Por fim, reforça-se a importância do desenvolvimento de metodologias como as apresentadas neste estudo, capazes de subsidiar diagnósticos permanentes em áreas de aglomerações urbanas. Tais instrumentos são imprescindíveis numa visão de planejamento urbano integrado que contemple ações locais e regionais capazes de responder à dinâmica e complexidade dessas áreas. 


\section{Referências}

Anas, A., Arnott, R., \& Small, K. (1998). Urban spatial structure. Journal of Economic Literature, 36, 1426-1464.

Associação Brasileira de Shopping Centers - ABRASCE. (2017). Plano de Mix 2017. Recuperado em 10 de março de 2018, de https://abrasce.com.br/wp-content/uploads/2019/05/AF-PlanoDeMix-2017_2018.pdf

Batty, M. (2008). Cities as complex systems. scalling, interactions, networks, dynamics and urban morphologies. Londres: CASA Paper 131.

Bento Gonçalves. (2006). Lei Complementar no 103, de 26 de outubro de 2006. Institui o Novo Plano Diretor de Desenvolvimento Integrado do Município de Bento Gonçalves. Bento Gonçalves: Diário Oficial do Município.

Berry, B. (1967). Geografia de los Centros de Mercado y Distribución al por Menor. Barcelona: Ed. Vicens-Vives.

Brasil. (2015). Lei n. 13.089, de 12 de janeiro de 2015. Institui o Estatuto da Metrópole, altera a Lei no 10.257, de 10 de julho de 2001, e dá outras providências. Brasília: Diário Oficial da União.

Camagni, R. (2005). Economia urbana. Barcelona: Asociación Española de Ciencia Regional.

Colusso, I. (2015). Forças regionais, formas urbanas e estrutura interna da cidade: um estudo de relações [Tese de doutorado]. Universidade Federal do Rio Grande do Sul, Porto Alegre.

Christaller, W. (1966). Central places in Southern Germany. Englewood Cliffs: Prentice-Hall.

Crucitti, P., Latora, V., \& Porta, S. (2006). Centrality measures in spatial networks of urban streets. Physical Review E, 73(3 Pt2), 036125. http://dx.doi.org/10.1103/PhysRevE.73.036125.

Davidovich, F. R., \& Lima, O. M. B. (1975). Contribuição ao estudo de aglomerações urbanas no Brasil. Revista Brasileira de Geografia, 37(1), 3-84.

Delgado, P. R., Deschamps, M. V., Vanice, M., Moura, R., \& Ulhôa Cintra, A. P. (2016). Mobilidades nas regiões metropolitanas brasileiras: processos migratórios e deslocamentos pendulares. In R. Balbim, C. Krause \& C. C. Linke. Cidade e movimento: mobilidades e interações no desenvolvimento urbano (pp. 223-245). Brasília: Ipea: ITDP.

ESRI ArcGIS. (2013). ESRI ArcGIS: versão 10.2 [Software] Redlands: ArcGIS.

Fujita, M., Krugman, P., \& Venables, A. J. (2002). Economia espacial. São Paulo: Ed. Futura.

Fundação Estadual de Planejamento Metropolitano e Regional - METROPLAN. (2013). Análise da Possibilidade de Transformação da Aglomeração Urbana do Nordeste - AUNe em Região Metropolitana de Caxias do Sul. Porto Alegre: METROPLAN. Recuperado em 20 de março de 2018, de

www.aune.rs.gov.br/index.php?option=com_weblinks\&view=category\&id=14\&Itemid=22

Google Fusion Tables. (2018). Recuperado em 20 de março de 2018, de

https://www.google.com/fusiontables/data?dsrcid=implicit\&pli=1

Hillier, B. (1999). Centrality as a process. Accounting for attraction inequalities in deformed grids. Urban Desing International, 4(3-4), 107-127.

Hillier, B., \& Hanson, J. (1984). The social logic of space. Cambridge: Cambridge University Press. http://dx.doi.org/10.1017/CB09780511597237.

Hillier, B., Penn, A., Hanson, J., Grajewski, T., \& Xu, J. (1993). Natural movement: or, configuration and attraction in urban pedestrian movement. Environment and Planning. B, Planning \& Design, 20(1), 29-66.

http://dx.doi.org/10.1068/b200029.

Instituto Brasileiro de Geografia e Estatística - IBGE. (2007). Regiões de influência das cidades - REGIC. Rio de Janeiro: IBGE. Recuperado em 06 de março de 2017, de http://www.mma.gov.br/estruturas/PZEE/_arquivos/regic_28.pdf

Instituto Brasileiro de Geografia e Estatística - IBGE. (2012). Censo demográfico 2010. Rio de Janeiro: IBGE. Recuperado em 27 de março de 2017, de https://censo2010.ibge.gov.br/resultados.html 
Instituto Brasileiro de Geografia e Estatística - IBGE. (2014). Estimativas populacionais. Rio de Janeiro: IBGE. Recuperado em 27 de março de 2017, de https://www.ibge.gov.br/estatisticasnovoportal/sociais/populacao/9103-estimativas-de-populacao.html

Instituto Brasileiro de Geografia e Estatística - IBGE. (2015). Arranjos Populacionais e Concentrações Urbanas do Brasil. Rio de Janeiro: IBGE. Recuperado em 20 de março de 2018, de https://biblioteca.ibge.gov.br/visualizacao/livros/liv99700.pdf

Jiang, B. (2008). Street hierarchies: a minority of streets account for a majority of traffic flow. International Journal of Geographical Information Science, 23(8), 1033-1048. http://dx.doi.org/10.1080/13658810802004648.

Krafta, R. (1994). Modelling intra-urban configurational development. Environment and Planning. B, Planning \& Design, 21(1), 67-82. http://dx.doi.org/10.1068/b210067.

Krafta, R. (2014). Notas de aula de morfologia urbana. Porto Alegre: Ed. Universidade Federal do Rio Grande do Sul. Lemos, M. B., Diniz, C. C., Guerra, L. P., \& Moro, S. (2003). A nova configuração regional brasileira e sua geografia econômica. Estudos Econômicos, 33(4), 665-700.

Maraschin, C. (2013). Reflexões acerca da descentralização do comércio. In Anais IV CINCci - Colóquio Internacional sobre Comércio e Cidade. São Paulo: FauUSP.

Motta, D. M., \& Ajara, C. (2001). Configuração da Rede Urbana no Brasil. Revista Paranaense de Desenvolvimento, 100, 7-25.

Polidori, M. C., Granero, J., \& Krafta, R. (2001). Medidas urbanas, versão 1.15. FAUrb [Software]. Pelotas: UFPel.

Porta, S., Strano, E., Iacoviello, V., Messora, R., Latora, V., Cardillo, A., Wang, F., \& Scellato, S. (2009). Street centrality and densities of retail and services in Bologna, Italy. Environment and Planning. B, Planning \& Design, 36(3), 450465. http://dx.doi.org/10.1068/b34098.

Programa das Nações Unidas para o Desenvolvimento - PNUD. (2010). IDHM Municípios. Recuperado em 20 de março de 2018, de http://www.atlasbrasil.org.br/2013/pt/ranking

Richardson, H. (1973). Elementos de economia regional. Rio de Janeiro: Zahar Ed.

Rigatti, D. (2009). Measuring conurbation. In Proceedings of the 7th International Space Syntax Symposium (pp. 113). Stockholm: School of Architecture, KTH.

Simões, R., \& Amaral, P. V. (2011). Interiorização e novas centralidades urbanas: uma visão prospectiva para o Brasil. Revista Economia, 12(3), 553-579.

Souza, M. L. (2008). ABC do desenvolvimento urbano. Rio de Janeiro: Bertrand Brasil.

Ugalde, C. M. (2013). Movimento e hierarquia espacial na conurbação: o caso da Região Metropolitana de Porto Alegre [Tese de doutorado]. Universidade Federal do Rio Grande do Sul, Porto Alegre.

Ultramari, C., \& Moura, R. (1994). Metrópole - Grande Curitiba: teoria e prática. Curitiba: IPARDES.

Villaça, F. (2001). Espaço Intra-Urbano no Brasil (2 ed.). São Paulo: Studio Nobel.

Wilson, A. G. (1971). A family of spatial interaction models, and associated developments. Environment \& Planning, 3(1), 1-32. http://dx.doi.org/10.1068/a030001.

Zechlinski, A. P. P. (2013). Configuração e práticas no espaço urbano: uma análise da estrutura espacial urbana [Tese de doutorado]. Universidade Federal do Rio Grande do Sul, Porto Alegre.

Editor: Rodrigo Firmino.

Recebido: Mar. 26, 2018

Aprovado: Jan. 23, 2019 